\title{
Development of Perfume Bottle Visual Design Model Using Fuzzy Analytic Hierarchy Process
}

\author{
Hung-Yuan Chen \\ Department of Visual Communication Design, Southern Taiwan University of Science and Technology, Taiwan \\ Email: hungyuan@stust.edu.tw
}

How to cite this paper: Chen, H.-Y. (2017). Development of Perfume Bottle Visual Design Model Using Fuzzy Analytic Hierarchy Process. Art and Design Review, 5, 13-25.

https://doi.org/10.4236/adr.2017.51002

Received: November 9, 2016

Accepted: January 7, 2017

Published: January 10, 2017

Copyright $\odot 2017$ by author and Scientific Research Publishing Inc. This work is licensed under the Creative Commons Attribution International License (CC BY 4.0).

http://creativecommons.org/licenses/by/4.0/

(c) (i) Open Access

\begin{abstract}
With the popularization of internet shopping, visualization of goods package has become an important factor in communicating goods characteristics and plays a critical role in influencing consumers' purchase decision. This phenomenon is particularly apparent in the case of mature consumer goods such as perfume products, chocolate, daily commodity, and so on. To construct a decision support model for assisting package designers to create a satisfying product package based on consumers' affective responses, a series of visual experiment evaluation for perfume bottle package is conducted in the current study. The fuzzy analytic hierarchy process-based approach is proposed to construct the decision support model for perfume bottle visual design. In the current study, the feasibility of constructing model based on the fuzzy analytic hierarchy process approach is demonstrated and the resulting model can provide perfume package designers with an understanding of developing a new design alternative in the conceptual design stage.
\end{abstract}

\section{Keywords}

Package Visual Design, Perfume Bottle, Multiple Consumers'

Psychological Perceptions

\section{Introduction}

A conspicuous or high quality package design is one way that a new product can stand out from familiar packages offered by the competition (Berkowitz, 1987). If the package design of a product communicates high aesthetic quality, consumers frequently assume that the product is high quality, and vice versa. Furthermore, consumers are likely to generate perceptional response to a product by means of its package, i.e. a product feels, looks, while viewing product package (Underwood et al., 2001). Thus, the consideration of consumers' psychological perception (CPP) to package visual design plays a critical role in purchase 
decisions since it communicates useful information to consumers at the decision making time. This phenomenon is particularly apparent in the case of mature consumer goods such as perfume products, chocolate, cosmetic, daily commodity, and so on. Therefore, it is essential for package designers or companies to comprehend consumers' psychological perception (CPP) to package design of a product and to develop a consumer-oriented visual design model so as to generate the suitable design alternatives during the conceptual design process.

Many package design studies have conducted systematic approach to construct a design model and to obtain a better understanding regarding CPP to package design of a product (Henson et al., 2006; Ares \& Deliza, 2010; Gofman et al., 2010; Metcalf et al., 2012; Fernqvist et al., 2015). In general, the effectiveness of the systematic design approach is crucially determined by the choice of analytical techniques. Techniques such as analytic hierarchy process (Lin et al., 2008), conjoint analysis (Ares \& Deliza, 2010; Demirtas et al., 2009) and quantitative theory type I (Lin \& Wei, 2014) are commonly employed. Analytic hierarchy process (AHP) is particularly useful to demonstrate the weight/utility of each design element by pairwise comparison method and the unsophisticated calculation process and it has high practicability in the conceptual design evaluation. However, the expression of CPP to package design of a product is commonly multiple and vague. AHP does not take into account the uncertainty of one's description to a number. To take the multiple CPPs and the imprecision of human linguistic expressions into consideration, the fuzzy set theory is introduced (Zadeh, 1994) to strengthen the capability of AHP to construct the visual design model which satisfies the requirements of multiple CPPs in this study.

An integrated approach which combines fuzzy set theory with AHP (designated hereafter as the Fuzzy AHP) is proposed to develop the decision support design model for perfume bottle visual design. The perfume product is chosen for illustration purposes since the consumers' purchase decision is governed not only by its perfume characteristic for use, but also by the affective response induced by its package. The remainder of this study is organized as follows: Section 2 reviews the background of AHP and fuzzy set theory. Section 3 presents the research implementation. Section 4 illustrates the construction of perfume bottle visual design model based on Fuzzy AHP. Section 5 presents a brief conclusion.

\section{Methodological Review}

\subsection{Analytic Hierarchy Process (AHP)}

Analytic hierarchy process (AHP) is a systematic and scientific method. It is able to order individual professional comments into a hierarchy and then analyze this hierarchy to increase the efficiency of the evaluation. A nine-point scale is frequently used to convert the participants' verbal responses or preferences by means of the options such as equally important (1), moderately important (3), strongly important (5), very strongly important (7), and extremely important (9) (Saaty, 1994). Although the nine-point scale has the advantages of simplicity and 
easiness for use, it does not take into account the uncertainty associated with the mapping of participants' perception to a number.

\subsection{Fuzzy Set Theory}

To take the imprecision of human qualitative evaluations into consideration, fuzzy set theory (Zadeh, 1994) is introduced to solve the problems involving the absence of sharply defined criteria. The key idea of fuzzy set theory is that an element has a degree of membership in a fuzzy set (Zimmermann, 1996). A fuzzy set is defined by a membership function. The most commonly used range for expressing the degree of membership is the unit interval $[0,1]$. Fuzzy set theory thus is used to solve such kind of problems, and it has been applied in a variety of fields. In this study, the triangular fuzzy number is used to represent subjective pairwise comparisons of selection process in order to capture the vagueness. As shown in Figure 1, the triangular fuzzy number $\tilde{A}=(l, m, u), 1$ and $\mathrm{u}$ mean the lower and upper bounds of the fuzzy number $\tilde{A}$, respectively, and $\mathrm{m}$ is the median value for $\tilde{A}$. The membership function is defined as Equation (1). The operational rules of addition and multiplication of $\tilde{A}_{1}=\left(l_{1}, m_{1}, u_{1}\right)$ and $\tilde{A}_{2}=\left(l_{2}, m_{2}, u_{2}\right)$ are displayed as following Equations (2) and (3).

$$
u_{\tilde{A}}(x)=\left\{\begin{array}{ll}
(x-l) /(m-l), & l \leq x \leq m \\
(x-u) /(m-u), & m \leq x \leq u \\
0, \text { otherwise, } & 0 \leq l \leq m \leq u
\end{array}\right\}
$$

Addition of the fuzzy number $\oplus$

$$
\tilde{A}_{1} \oplus \tilde{A}_{2}=\left(l_{1}, m_{1}, u_{1}\right) \oplus\left(l_{2}, m_{2}, u_{2}\right)=\left(l_{1+} l_{2}, m_{1+} m_{2}, u_{1+} u_{2}\right)
$$

Multiplication of the fuzzy number $\otimes$

$$
\begin{aligned}
& \tilde{A}_{1} \otimes \tilde{A}_{2}=\left(l_{1}, m_{1}, u_{1}\right) \otimes\left(l_{2}, m_{2}, u_{2}\right)=\left(l_{1} l_{2}, m_{1} m_{2}, u_{1} u_{2}\right) \\
& \text { for } l_{1} ; l_{2}>0 ; m_{1} ; m_{2}>0 ; u_{1} ; u_{2}>0
\end{aligned}
$$

\subsection{Fuzzy AHP}

From the discussions above, this study proposes an integrated scheme, combining fuzzy set theory with AHP (Fuzzy AHP). The triangular fuzzy numbers parameterized by triplet numbers are used to represent the perfume bottle evaluation of multiple affective responses as well as to construct the pairwise comparison matrix. The procedure of Fuzzy AHP is described as follows.

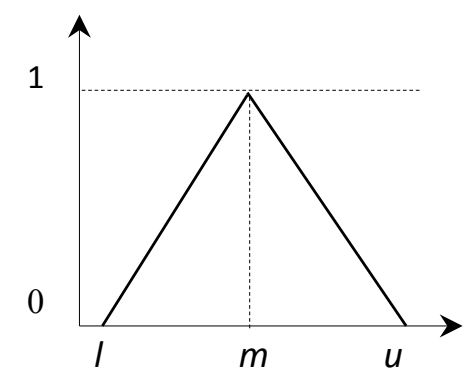

Figure 1. Triangular fuzzy number. 
Step 1: Constructing the fuzzy judgment matrix and determining the weight vector: The fuzzy judgment matrix $A$ is the matrix of the combination of $m$ candidate alternative and $n$ evaluation criteria and the weight vector $W$ based on $n$ evaluation criteria is constructed as following Equations (4) and (5). The elements of the fuzzy judgment matrix $A$ and weight vector $W$ are represented by five triangular fuzzy numbers, i.e. $\tilde{1}-\tilde{9}$. The five triangular fuzzy numbers are defined with the corresponding membership function and the meaning as shown in Table 1 . Then, WT is the transpose of the weight vector $W$ and it can be described as Equation (6).

$$
\begin{gathered}
\boldsymbol{A}=\left[a_{i j}\right]_{m \times n}=\left[\begin{array}{cccc}
\tilde{a}_{11} & \tilde{a}_{21} & \cdots & \tilde{a}_{1 n} \\
\tilde{a}_{21} & \tilde{a}_{22} & \cdots & \tilde{a}_{2 n} \\
\vdots & \vdots & \ddots & \vdots \\
\tilde{a}_{m 1} & \tilde{a}_{m 2} & \cdots & \tilde{a}_{m n}
\end{array}\right] \\
\boldsymbol{W}=\left[\tilde{w}_{j}\right]_{1 \times n}=\left[\begin{array}{llll}
\tilde{w}_{1} & \tilde{w}_{2} & \cdots & \tilde{w}_{n}
\end{array}\right] \\
\boldsymbol{W}^{\mathrm{T}}=\left[\begin{array}{c}
\tilde{w}_{1} \\
\tilde{w}_{2} \\
\vdots \\
\tilde{w}_{n}
\end{array}\right]
\end{gathered}
$$

Step 2: Constructing the weighted fuzzy judgment matrix and calculating the final fuzzy scores of candidate alternatives: The weighted fuzzy judgment matrix can be obtained by means of Equation (7). Based on the result of Equation (7) calculation using the operational rules of Equation (2) and Equation (3), the fuzzy sequencing vector $S$, show as $\left[\tilde{s}_{i}\right]_{m \times 1}$, can be obtained. Then, the $\tilde{s}_{i}$ of fuzzy sequencing vector is the final fuzzy scores of the candidate alternatives.

$$
\boldsymbol{S}=A \otimes W^{\mathrm{T}}=\left[\begin{array}{cccc}
\tilde{a}_{11} & \tilde{a}_{21} & \cdots & \tilde{a}_{1 n} \\
\tilde{a}_{21} & \tilde{a}_{22} & \cdots & \tilde{a}_{2 n} \\
\vdots & \vdots & \ddots & \vdots \\
\tilde{a}_{m 1} & \tilde{a}_{m 2} & \cdots & \tilde{a}_{m n}
\end{array}\right] \otimes\left[\begin{array}{c}
\tilde{w}_{1} \\
\tilde{w}_{2} \\
\vdots \\
\tilde{w}_{n}
\end{array}\right]=\left[\begin{array}{c}
\tilde{s}_{1} \\
\tilde{s}_{2} \\
\vdots \\
\tilde{s}_{m}
\end{array}\right]
$$

Step 3: Defuzzifying the fuzzy scores and ranking the candidate alternatives: It is necessary to define a method for building a crisp ordering of $\tilde{s}_{i}$ to rank the candidate alternative since the final fuzzy scores of candidate alternatives are the type of fuzzy numbers. In this study, the fuzzy numbers are defuzzified and ranked by the fuzzy mean value (Wu et al., 2004). $\tilde{s}_{i}$ is a triangular fuzzy number $(l, m, u)$. Its mean $\overleftrightarrow{x}\left(\tilde{s}_{i}\right)$ is defined as Equation (8).

Table 1. Definition of relative fuzzy number and membership function

\begin{tabular}{ccc}
\hline Fuzzy number & Meaning & Membership function \\
\hline$\tilde{1}$ & Equally important & $(1,1,3)$ \\
$\tilde{3}$ & Moderately important & $(1,3,5)$ \\
$\tilde{5}$ & Strongly important & $(3,5,7)$ \\
$\tilde{7}$ & Very strongly important & $(5,7,9)$ \\
$\tilde{9}$ & Extremely important & $(7,9,9)$
\end{tabular}




$$
\overleftrightarrow{x}\left(\tilde{s}_{i}\right)=(l+m+u) / 3
$$

Then, the fuzzy numbers $\tilde{s}_{1}, \tilde{s}_{2}, \cdots, \tilde{s}_{m}$ can be ranked according to the value of the fuzzy mean $\overleftrightarrow{x}\left(\tilde{s}_{i}\right)$ to determine the optimum candidate alternative.

\section{Research Implementation}

\subsection{Constructing Qualitative Definitions of Perfume Bottle}

To explore the consumers' psychological perceptions (CPPs) to perfume bottle visual design, approximately one hundred commercially-available perfume bottle pictures with similar view-angles are collected in this study. The discussion of focus group (McDonagh et al., 2002) involving 5 package/graphic designers is conducted to classify the perfume bottle pictures based on the similarity of their appearance, and 53 perfume bottle pictures shown as Figure 2 are retained in accordance with the visual dissimilarity of perfume bottle. Then, the morphological analysis is used to define the perfume bottle into several dominant design elements and features based on the experiences of 5 designers by means of a discussion. Table 2 presents the 8 important design elements which are finally determined, and their corresponding features.

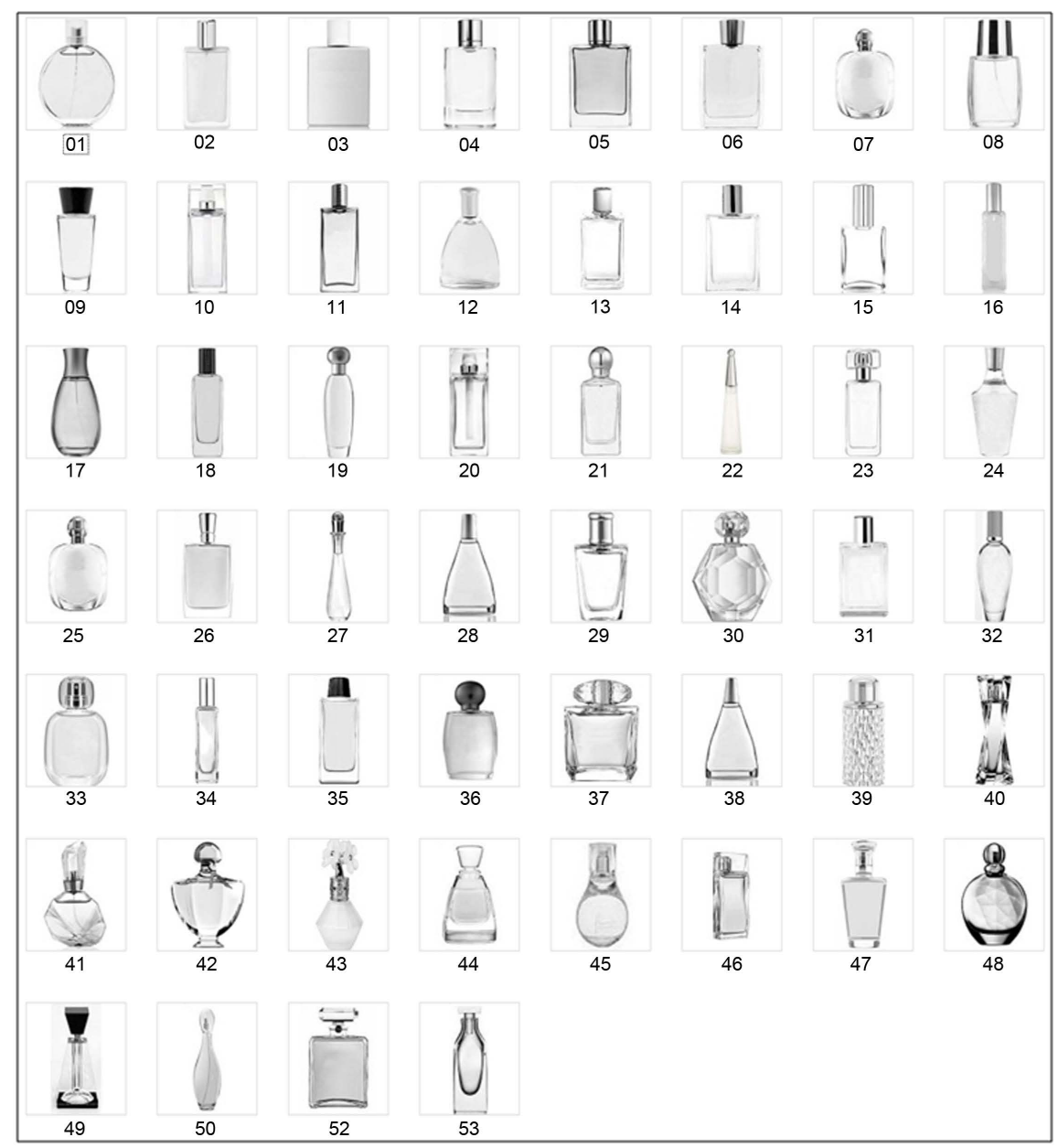

Figure 2. Fifty-three existing perfume bottle samples. 
Table 2. Definition of perfume bottle visual design.

\begin{tabular}{|c|c|c|c|c|c|}
\hline $\begin{array}{l}\text { Features } \\
\text { Elements }\end{array}$ & Type 1 & Type 2 & Type 3 & Type 4 & Type 5 \\
\hline $\begin{array}{c}\text { Shape of } \\
\text { bottle cap }\left(X_{1}\right)\end{array}$ & $\begin{array}{l}\text { Square } \\
\left(X_{11}\right)\end{array}$ & $\begin{array}{l}\text { Sphere } \\
\left(X_{12}\right)\end{array}$ & $\begin{array}{c}\text { Trapezoid } \\
\left(X_{13}\right)\end{array}$ & $\begin{array}{c}\text { Inverse } \\
\text { trapezoid }\left(X_{14}\right)\end{array}$ & \\
\hline $\begin{array}{l}\text { Material of bottle cap } \\
\qquad\left(X_{2}\right)\end{array}$ & $\begin{array}{l}\text { Glass } \\
\left(X_{21}\right)\end{array}$ & $\begin{array}{l}\text { Plastic } \\
\left(X_{22}\right)\end{array}$ & & & \\
\hline $\begin{array}{c}\text { Surface of } \\
\text { bottle cap }\left(X_{3}\right)\end{array}$ & $\begin{array}{c}\text { Transparent } \\
\operatorname{effect}\left(X_{31}\right)\end{array}$ & $\begin{array}{l}\text { Semiopaque } \\
\text { effect }\left(X_{32}\right)\end{array}$ & $\begin{array}{c}\text { Plating effect } \\
\left(X_{33}\right)\end{array}$ & $\begin{array}{l}\text { Facet effect } \\
\qquad\left(X_{34}\right)\end{array}$ & \\
\hline $\begin{array}{l}\text { Width-to-height } \\
\text { proportion of bottle } \\
\text { cap shape }\left(X_{4}\right)\end{array}$ & $\begin{array}{c}2: 1 \\
\left(X_{41}\right)\end{array}$ & $\begin{array}{c}1: 1 \\
\left(X_{42}\right)\end{array}$ & $\begin{array}{c}1: 0.67 \\
\left(X_{43}\right)\end{array}$ & $\begin{array}{l}1: 0.5 \\
\left(X_{44}\right)\end{array}$ & \\
\hline $\begin{array}{c}\text { Shape of } \\
\text { bottle body }\left(X_{5}\right)\end{array}$ & $\begin{array}{l}\text { Square } \\
\left(X_{51}\right)\end{array}$ & $\begin{array}{l}\text { Circle } \\
\left(X_{52}\right)\end{array}$ & $\begin{array}{c}\text { Trapezoid } \\
\left(X_{53}\right)\end{array}$ & $\begin{array}{c}\text { Inverse } \\
\text { trapezoid }\left(X_{54}\right)\end{array}$ & $\begin{array}{l}\text { Hexagon } \\
\left(X_{55}\right)\end{array}$ \\
\hline $\begin{array}{c}\text { Surface of } \\
\text { bottle body }\left(X_{6}\right)\end{array}$ & $\begin{array}{l}\text { Transparent } \\
\text { effect }\left(X_{61}\right)\end{array}$ & $\begin{array}{l}\text { Semiopaque } \\
\text { effect }\left(X_{62}\right)\end{array}$ & $\begin{array}{l}\text { Facet effect } \\
\qquad\left(X_{63}\right)\end{array}$ & & \\
\hline $\begin{array}{l}\text { Width-to-height } \\
\text { proportion of bottle } \\
\text { body shape }\left(X_{7}\right)\end{array}$ & $\begin{array}{c}2: 1 \\
\left(X_{71}\right)\end{array}$ & $\begin{array}{c}1: 1 \\
\left(X_{72}\right)\end{array}$ & $\begin{array}{c}1: 0.67 \\
\left(X_{73}\right)\end{array}$ & $\begin{array}{l}1: 0.5 \\
\left(X_{74}\right)\end{array}$ & \\
\hline $\begin{array}{l}\text { Proportion of cap } \\
\text { shape height to body } \\
\text { shape height }\left(X_{8}\right)\end{array}$ & $\begin{array}{c}3: 1 \\
\left(X_{81}\right)\end{array}$ & $\begin{array}{c}1: 2 \\
\left(X_{82}\right)\end{array}$ & $\begin{array}{c}1: 1 \\
\left(X_{83}\right)\end{array}$ & & \\
\hline
\end{tabular}

\subsection{Creating Evaluation Samples of Perfume Bottle}

In order to accommodate the 8 design elements and the corresponding features, the orthogonal design is conducted to array the conditions of evaluation samples in this study. The result of orthogonal design is shown in Table 3. Subsequently, three package/graphic designers, each with more than three years' of design experience are invited to create the perfume bottle evaluation samples based on the qualitative definition scheme shown in Table 2. As shown in Figure 3, a total of 32 samples are created for evaluation of perfume bottle image.

\subsection{Selecting Representative Consumers' Psychological Perceptions}

Although many different image words are used when describing commodity package, the image words applicable to perfume bottle are more limited. In this study, 3 package/graphic designers, each with 3 years experience (two males and one female), and 3 white-collar individuals from non-design backgrounds (one male and two females) are invited to participate in a discussion aimed at identifying suitable image words with which to describe the possible consumers' psychological perceptions (CPPs) when presented with the perfume bottle samples. The image words are elicited from the participants using the following four-step procedure:

Step 1: The 53 perfume bottle samples are reviewed, and the image words (in Chinese) used by the individual participants to describe their CPPs of the image projected by each perfume bottle are recorded. 
Table 3. Orthogonal design of perfume bottle samples.

\begin{tabular}{|c|c|c|c|c|c|c|c|c|}
\hline Evaluation Samples & $X_{1}$ & $X_{2}$ & $X_{3}$ & $X_{4}$ & $X_{5}$ & $X_{6}$ & $X_{7}$ & $X_{8}$ \\
\hline No. 1 & $X_{12}$ & $X_{22}$ & $X_{31}$ & $X_{41}$ & $X_{54}$ & $X_{62}$ & $X_{73}$ & $X_{83}$ \\
\hline No. 2 & $X_{11}$ & $X_{22}$ & $X_{33}$ & $X_{41}$ & $X_{52}$ & $X_{62}$ & $X_{72}$ & $X_{81}$ \\
\hline No. 3 & $X_{14}$ & $X_{21}$ & $X_{34}$ & $X_{44}$ & $X_{51}$ & $X_{61}$ & $X_{74}$ & $X_{81}$ \\
\hline No. 4 & $X_{12}$ & $X_{21}$ & $X_{33}$ & $X_{44}$ & $X_{52}$ & $X_{63}$ & $X_{72}$ & $X_{82}$ \\
\hline No. 5 & $X_{11}$ & $X_{22}$ & $X_{34}$ & $X_{42}$ & $X_{54}$ & $X_{62}$ & $X_{73}$ & $X_{81}$ \\
\hline No. 6 & $X_{11}$ & $X_{21}$ & $X_{32}$ & $X_{43}$ & $X_{53}$ & $X_{61}$ & $X_{72}$ & $X_{83}$ \\
\hline No. 7 & $X_{11}$ & $X_{22}$ & $X_{34}$ & $X_{43}$ & $X_{55}$ & $X_{61}$ & $X_{71}$ & $X_{82}$ \\
\hline No. 8 & $X_{14}$ & $X_{22}$ & $X_{32}$ & $X_{41}$ & $X_{55}$ & $X_{63}$ & $X_{71}$ & $X_{82}$ \\
\hline No. 9 & $X_{14}$ & $X_{21}$ & $X_{33}$ & $X_{42}$ & $X_{53}$ & $X_{61}$ & $X_{73}$ & $X_{82}$ \\
\hline No. 10 & $X_{13}$ & $X_{22}$ & $X_{34}$ & $X_{41}$ & $X_{53}$ & $X_{63}$ & $X_{74}$ & $X_{82}$ \\
\hline No. 11 & $X_{13}$ & $X_{21}$ & $X_{31}$ & $X_{43}$ & $X_{52}$ & $X_{62}$ & $X_{74}$ & $X_{82}$ \\
\hline No. 12 & $X_{13}$ & $X_{21}$ & $X_{32}$ & $X_{41}$ & $X_{52}$ & $X_{62}$ & $X_{73}$ & $X_{81}$ \\
\hline No. 13 & $X_{12}$ & $X_{22}$ & $X_{32}$ & $X_{42}$ & $X_{54}$ & $X_{62}$ & $X_{72}$ & $X_{82}$ \\
\hline No. 14 & $X_{13}$ & $X_{21}$ & $X_{32}$ & $X_{44}$ & $X_{54}$ & $X_{61}$ & $X_{71}$ & $X_{83}$ \\
\hline No. 15 & $X_{11}$ & $X_{22}$ & $X_{33}$ & $X_{44}$ & $X_{55}$ & $X_{62}$ & $X_{74}$ & $X_{83}$ \\
\hline No. 16 & $X_{12}$ & $X_{21}$ & $X_{34}$ & $X_{42}$ & $X_{52}$ & $X_{63}$ & $X_{71}$ & $X_{83}$ \\
\hline No. 17 & $X_{14}$ & $X_{21}$ & $X_{33}$ & $X_{43}$ & $X_{55}$ & $X_{62}$ & $X_{71}$ & $X_{81}$ \\
\hline No. 18 & $X_{13}$ & $X_{21}$ & $X_{31}$ & $X_{42}$ & $X_{55}$ & $X_{6 I}$ & $X_{72}$ & $X_{83}$ \\
\hline No. 19 & $X_{13}$ & $X_{22}$ & $X_{33}$ & $X_{42}$ & $X_{51}$ & $X_{63}$ & $X_{71}$ & $X_{81}$ \\
\hline No. 20 & $X_{13}$ & $X_{22}$ & $X_{34}$ & $X_{44}$ & $X_{53}$ & $X_{61}$ & $X_{72}$ & $X_{82}$ \\
\hline No. 21 & $X_{14}$ & $X_{22}$ & $X_{32}$ & $X_{44}$ & $X_{52}$ & $X_{61}$ & $X_{73}$ & $X_{83}$ \\
\hline No. 22 & $X_{12}$ & $X_{21}$ & $X_{34}$ & $X_{43}$ & $X_{55}$ & $X_{61}$ & $X_{73}$ & $X_{81}$ \\
\hline No. 23 & $X_{13}$ & $X_{22}$ & $X_{33}$ & $X_{43}$ & $X_{51}$ & $X_{63}$ & $X_{73}$ & $X_{83}$ \\
\hline No. 24 & $X_{12}$ & $X_{22}$ & $X_{31}$ & $X_{44}$ & $X_{53}$ & $X_{62}$ & $X_{71}$ & $X_{81}$ \\
\hline No. 25 & $X_{11}$ & $X_{21}$ & $X_{31}$ & $X_{44}$ & $X_{51}$ & $X_{63}$ & $X_{73}$ & $X_{82}$ \\
\hline No. 26 & $X_{12}$ & $X_{22}$ & $X_{32}$ & $X_{43}$ & $X_{51}$ & $X_{61}$ & $X_{74}$ & $X_{81}$ \\
\hline No. 27 & $X_{12}$ & $X_{21}$ & $X_{33}$ & $X_{41}$ & $X_{54}$ & $X_{63}$ & $X_{74}$ & $X_{82}$ \\
\hline No. 28 & $X_{11}$ & $X_{21}$ & $X_{31}$ & $X_{41}$ & $X_{51}$ & $X_{61}$ & $X_{71}$ & $X_{81}$ \\
\hline No. 29 & $X_{14}$ & $X_{22}$ & $X_{31}$ & $X_{43}$ & $X_{54}$ & $X_{63}$ & $X_{72}$ & $X_{81}$ \\
\hline No. 30 & $X_{14}$ & $X_{21}$ & $X_{34}$ & $X_{41}$ & $X_{51}$ & $X_{62}$ & $X_{72}$ & $X_{83}$ \\
\hline No. 31 & $X_{11}$ & $X_{21}$ & $X_{32}$ & $X_{42}$ & $X_{53}$ & $X_{63}$ & $X_{74}$ & $X_{81}$ \\
\hline No. 32 & $X_{14}$ & $X_{22}$ & $X_{31}$ & $X_{42}$ & $X_{52}$ & $X_{61}$ & $X_{74}$ & $X_{83}$ \\
\hline
\end{tabular}

Step 2: The Focus Group method is applied to select 25 suitable image words (see Figure 4) for the perfume bottles.

Step 3: The Kawakida Jirou (K.J.) technique (Cross, 1994) is then applied to classify the 25 image words in accordance with their semantic similarities by means of the discussion of focus group. As shown in Figure 4, three basic groups are identified. 


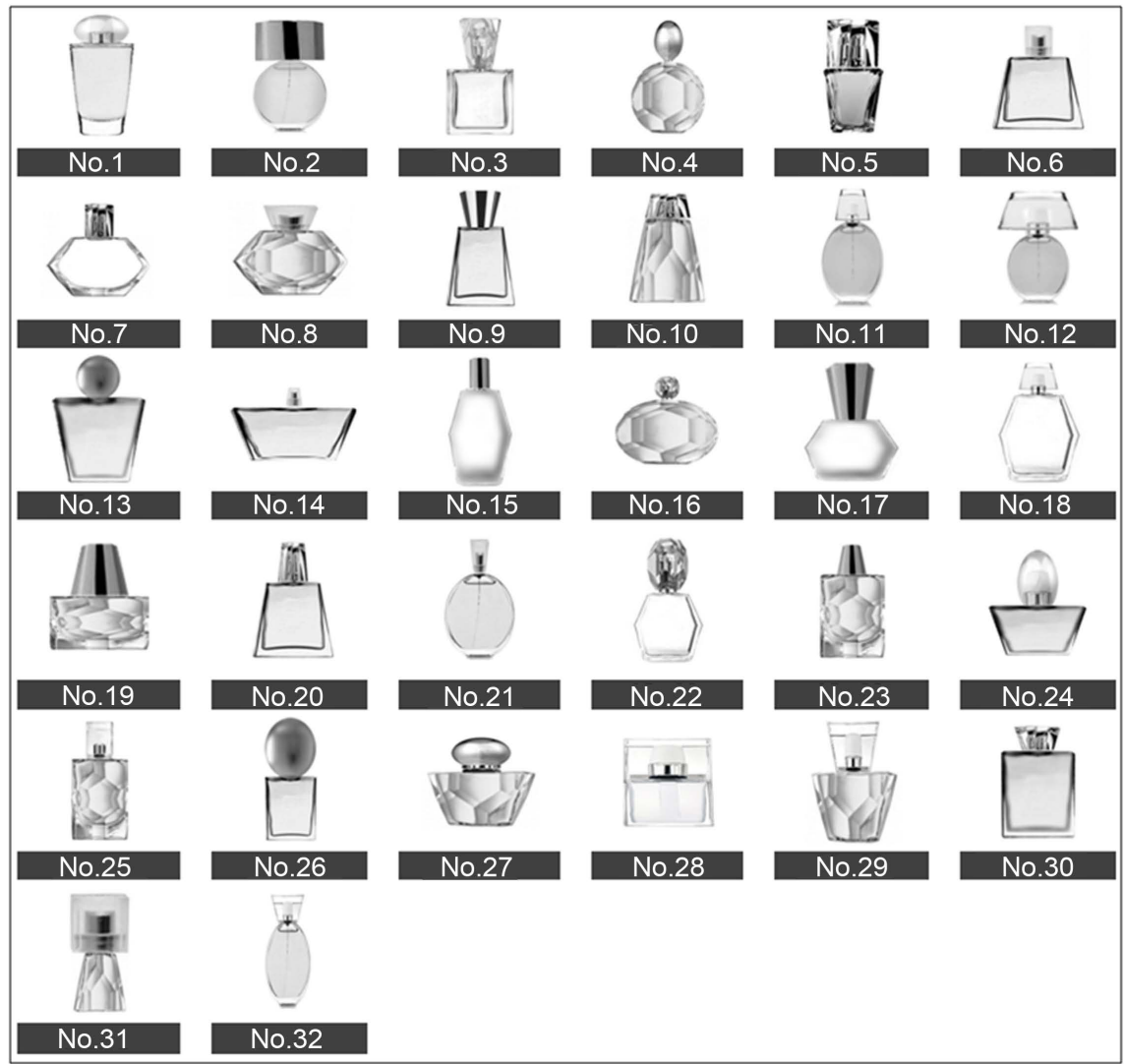

Figure 3. Thirty-two perfume bottle evaluation samples.

\begin{tabular}{|c|c|c|c|}
\hline \multirow{2}{*}{ Youthful } & \multicolumn{2}{|c|}{ Youthful and Vigorous } \\
\hline & Vigorous & Personal & Sprightly \\
\hline Cheerful & Spirited & Nimble & Peculiar \\
\hline & Feminine and Graceful & \\
\hline Feminine & Graceful & Elegant & Sexy \\
\hline Slender & Delicate & Alluring & Noble \\
\hline Gorgeous & Gentle & & \\
\hline Modern & Novel & Progressive & Prevalent \\
\hline Innovative & Concise & Succinct & \\
\hline
\end{tabular}

Figure 4. Selection and classification of image descriptors.

Step 4: From each group, one image words is chosen to represent the overall characteristics of the group, i.e. Youthful and Vigorous (Y. \& V.), Feminine and Graceful (F. \& G.), Modern and Novel (M. \& N.). 


\subsection{Perfume Bottle Visual Evaluation}

Eighty-four subjects (54 males, 33 females; age from 19 to 34 years old) are invited to evaluate the CPPs induced by the perfume bottles. The three representative CPPs are quantified using three 5-point scales. The 32 perfume bottle samples and the three 5-point scales are integrated into an interface constructed by using Visual Basic software, as shown in Figure 5. After each subject had evaluated all of the samples, the evaluative data are recorded for the usage of establishing the perfume bottle visual design model.

\subsection{Modeling the Correlation between Perfume Bottle and Consumers' Psychological Perceptions}

To construct a systematic design model respecting CPP to the visual effect of perfume bottle, the evaluation results obtained for the visual evaluation of perfume bottle are used to establish the correlation between perfume bottle and CPP. Since the data of evaluation results are the 5-point scale average values of eighty-four subjects in each of three CPPs, the proper fuzzy numbers are then defined to represent the 5-point scale average values as shown in Table 4. Fur-

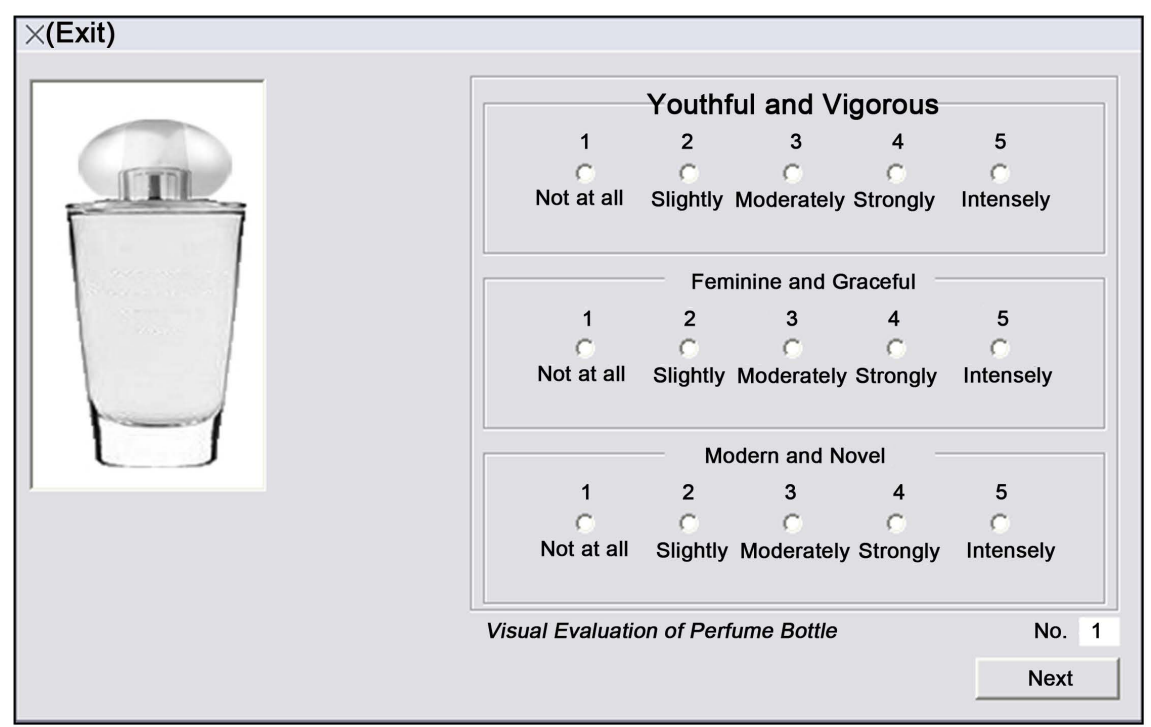

Figure 5. Perfume bottle evaluation interface.

Table 4. Definition of 5-point scale average values and verbal expression correspond to fuzzy number.

\begin{tabular}{cccc}
\hline 5-point scale average value & Verbal expression & Fuzzy number & Membership function \\
\hline Below 2.09 & Not at all (1) & $\tilde{1}$ & $(1,1,3)$ \\
$2.10-2.89$ & Slightly (2) & $\tilde{3}$ & $(1,3,5)$ \\
$2.90-3.69$ & Moderately (3) & $\tilde{5}$ & $(3,5,7)$ \\
$3.70-4.49$ & Strongly (4) & $\tilde{7}$ & $(5,7,9)$ \\
Above 4.5 & Intensely so (5) & $\tilde{9}$ & $(7,9,9)$ \\
\hline
\end{tabular}


thermore, this study treats the task of satisfying CPP to perfume bottle as a multi-objective design activity. Therefore, the Fuzzy AHP is introduced to analyze and to determine the optimum perfume bottle alternative which satisfy multiple $\mathrm{CPP}$ requirements.

\section{Construction of Perfume Bottle Visual Design Model}

\subsection{Constructing the Fuzzy Judgment Matrix and Determining the Weight Vector for Perfume Bottle Evaluation}

In constructing the perfume bottle visual design model using Fuzzy AHP, the average values (see Table 5) of the three CPPs obtained in the evaluation trials described in Section 3.3 are uniformly convert into the fuzzy number based on the definition of the first column of Table 4. For example, in sample 1, the average values of the three CPPs, i.e. "Y. \& V.", "F. \& G." and "M. \& N.", are 2.98, 2.25 and 3.52, respectively. According to the definition of first column of Table 4 and Equation (4), the average values of the three CPPs in sample 1 can be represented by a fuzzy number, and, respectively. Then, the fuzzy judgment matrix $A$ for perfume bottle can be shown below.

$$
A_{\text {perfume bottle }}=\left[\begin{array}{ccc}
\tilde{3} & \tilde{3} & \tilde{5} \\
\tilde{3} & \tilde{3} & \tilde{5} \\
\tilde{5} & \tilde{1} & \tilde{3} \\
\tilde{5} & \tilde{5} & \tilde{7} \\
\vdots & \vdots & \vdots \\
\tilde{3} & \tilde{5} & \tilde{7} \\
\tilde{3} & \tilde{5} & \tilde{3} \\
\tilde{1} & \tilde{3} & \tilde{3}
\end{array}\right]
$$

With respect to the weight decision, a set of specific multiple CPPs to perfume bottle are hypothetically designated by consumer groups or package designers in this study. For example, if a particular consumer group expects a new perfume bottle with "strongly Y. \& V." (4), "slightly F. \& G." (2), and "moderately M. \& N." (3). According to the definition of second column of Table 4, and Equation (5), the fuzzy weight vector $W$ for perfume bottle can be represented below.

Table 5. Average values and the corresponding fuzzy number for 32 perfume bottle samples.

\begin{tabular}{cccccccccc}
\hline \multirow{2}{*}{ Sample No. } & \multicolumn{3}{c}{ Y. \& V. } & \multicolumn{3}{c}{ F. \& G. } & \multicolumn{3}{c}{ M. \& N. } \\
\cline { 2 - 9 } & Avg & Sd & Fn & Avg & Sd & Fn & Avg & Sd & Fn \\
\hline 1 & 2.98 & \pm 0.93 & $\tilde{3}$ & 2.25 & \pm 0.94 & $\tilde{3}$ & 3.52 & \pm 0.86 & $\tilde{5}$ \\
2 & 2.06 & \pm 1.02 & $\tilde{1}$ & 2.12 & \pm 0.72 & $\tilde{3}$ & 3.36 & \pm 0.79 & $\tilde{5}$ \\
3 & 3.05 & \pm 0.78 & $\tilde{5}$ & 1.72 & \pm 0.66 & $\tilde{1}$ & 2.42 & \pm 1.08 & $\tilde{3}$ \\
4 & 3.61 & \pm 0.81 & $\tilde{5}$ & 3.46 & \pm 1.03 & $\tilde{5}$ & 3.92 & \pm 0.69 & $\tilde{7}$ \\
$\vdots$ & $\vdots$ & $\vdots$ & $\vdots$ & $\vdots$ & $\vdots$ & $\vdots$ & $\vdots$ & $\vdots$ & $\vdots$ \\
30 & 2.81 & \pm 0.69 & $\tilde{3}$ & 3.05 & \pm 0.76 & $\tilde{5}$ & 3.97 & \pm 0.87 & $\tilde{7}$ \\
31 & 2.31 & \pm 0.91 & $\tilde{3}$ & 3.77 & \pm 0.93 & $\tilde{5}$ & 2.93 & \pm 0.71 & $\tilde{3}$ \\
32 & 2.03 & \pm 0.93 & $\tilde{1}$ & 2.31 & \pm 0.96 & $\tilde{3}$ & 2.19 & \pm 1.12 & $\tilde{3}$ \\
\hline
\end{tabular}

The "Avg", "Sd" and "Fn" indicate the "Average value", "Standard deviation" and "Fuzzy number", respectively. 


$$
\boldsymbol{W}_{\text {Perfume Bottle }}=\left[\begin{array}{ccc}
\tilde{7} & \tilde{3} & \tilde{5}
\end{array}\right]
$$

\subsection{Constructing the Weighted Fuzzy Judgment Matrix and Calculating the Fuzzy Scores of Perfume Bottle}

Subsequently, $\boldsymbol{W}^{\mathrm{T}}$ for perfume bottle can be obtained from the transpose of the weight vector $W$, and the weighted fuzzy judgment matrix can be constructed based on Equation (7). Then, the fuzzy scores of perfume bottle can be calculated by using the fuzzy sequencing vector $S_{\text {perfume bottle }}$ shown below.

$$
\boldsymbol{S}_{\text {Perfume Bottle }}=\left[\begin{array}{ccc}
\tilde{3} & \tilde{3} & \tilde{5} \\
\tilde{1} & \tilde{3} & \tilde{5} \\
\tilde{5} & \tilde{1} & \tilde{3} \\
\tilde{5} & \tilde{5} & \tilde{7} \\
\vdots & \vdots & \vdots \\
\tilde{3} & \tilde{5} & \tilde{7} \\
\tilde{3} & \tilde{5} & \tilde{3} \\
\tilde{1} & \tilde{3} & \tilde{3}
\end{array}\right] \otimes\left[\begin{array}{c}
\tilde{7} \\
\tilde{3} \\
\tilde{5}
\end{array}\right]=\left[\begin{array}{c}
(15,55,119) \\
(15,41,101) \\
(19,53,113) \\
(33,85,161) \\
\vdots \\
(23,71,143) \\
(11,51,115) \\
(9,31,87)
\end{array}\right]
$$

\subsection{Defuzzifying the Fuzzy Scores and Ranking the Perfume Bottle Alternatives}

Finally, the defuzzification process is calculated in this step of the current study. Based on Equation (8): $\vec{x}\left(\tilde{s}_{i}\right)=(l+m+u) / 3$, the mean values of the triangular fuzzy numbers $(l, m, u)$ for each perfume bottle sample can be obtained by calculating the fuzzy number of fuzzy sequencing vector $S_{\text {Perfume Bottle }}$. Accordingly, the 32 perfume bottle samples can be ranked the highest to lowest based on their fuzzy mean values. As an illustration, Table 6 shows the top 5 ranking perfume bottle alternatives, and Figure 6 shows the optimum combination of the deign elements and their corresponding features for top 1 alternative. This result shows that the designers should consider "the trapezoid shape", "the glass material", "the transparent effect" and "approximately 1:1 proportion of width-toheight" for perfume bottle cap design, and "the hexagon shape", "the transparent effect" and "approximately 1:0.67 proportion of width-to-height" for perfume bottle body, and "approximately 3:1" for the proportion of cap shape height to body shape height when creating perfume bottle prototype designed to satisfy the "strongly Y. \& V.", "slightly F. \& G." and "moderately M. \& N." of multiple CPPs in the conceptual design stage.

Table 6. Result of defuzzification and ranking alternatives.

\begin{tabular}{cccccc}
\hline \multirow{2}{*}{ Rank } & Perfume Bottle No. & \multicolumn{3}{c}{ Fuzzy number $\left(\tilde{s}_{i}\right)$} & \multirow{2}{*}{ Fuzzy mean $\vec{x}_{(}\left(\tilde{s}_{i}\right)$} \\
\cline { 3 - 5 } & & $l$ & $m$ & $u$ & \\
\hline 1 & 18 & 57 & 117 & 169 & 114 \\
2 & 25 & 57 & 107 & 169 & 109 \\
3 & 27 & 41 & 101 & 171 & 104 \\
4 & 9 & 39 & 95 & 175 & 103 \\
5 & 16 & 39 & 95 & 161 & 98 \\
\hline
\end{tabular}




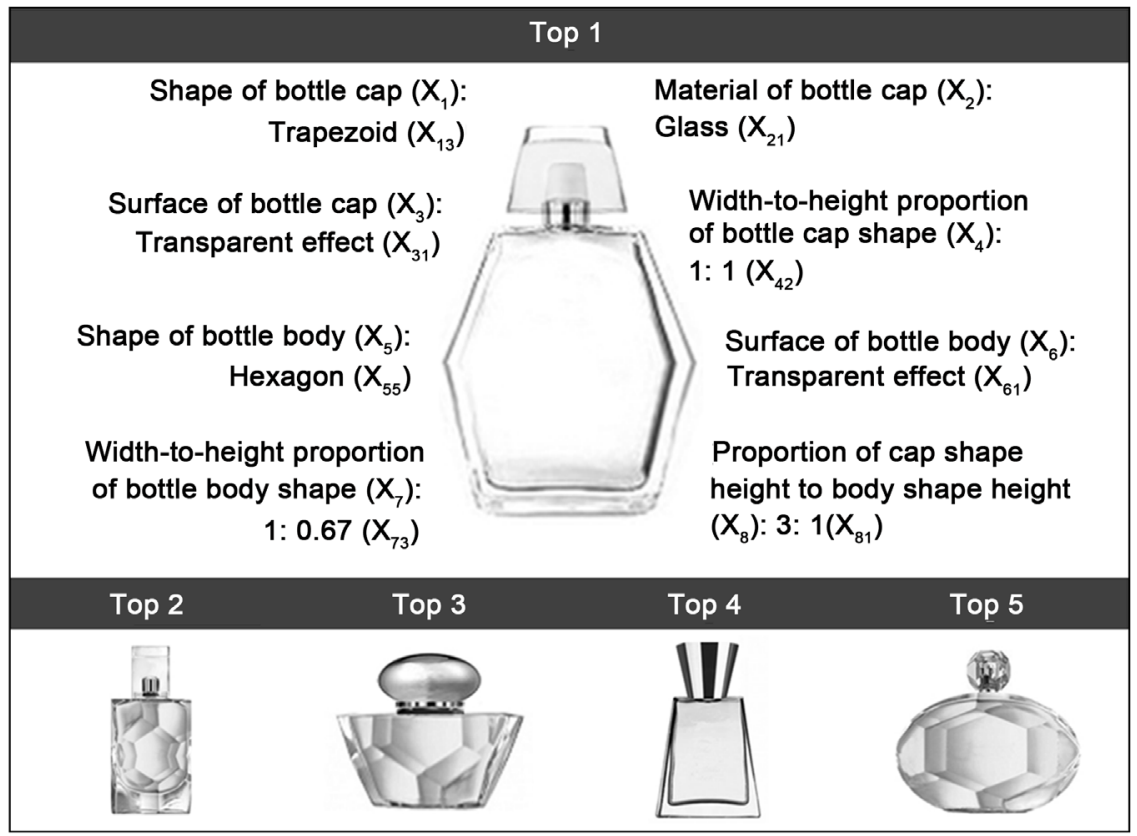

Figure 6. Top 5 perfume bottle alternatives.

\section{Conclusion}

This study has conducted a perfume bottle evaluation to develop the Fuzzy AHP-based design support model based on multiple CPPs. One of contributions of this study consists in proposing an integrated approach based on fuzzy set theory and analytic hierarchy process for modeling the correlation between perfume bottle and multiple CPPs. Moreover, the integrated approach can be extended to develop a design support model and to present the suitable design elements and design features for perfume bottle visual design. Accordingly, the development of design support model can assist package designers to obtain the prototype of optimum perfume bottle alternatives in the conceptual design stage. Furthermore, the Fuzzy AHP-based design support model in conjunction with the computer aided design system can facilitate the new perfume bottle design process. Overall, this Fuzzy AHP-based approach provides an effective mechanism for the package visual design of perfume bottle. In future studies, the generality of the design model constructed by Fuzzy AHP approach could be investigated by considering a variety of consumer goods examples.

\section{Acknowledgements}

Author gratefully acknowledges the subjects who participated in the evaluation trials and the support provided to this study by the Ministry of Science and Technology of Taiwan under Grant No. MOST 105-2410-H-218-007.

\section{References}

Berkowitz, M. (1987). Product Shape as a Design Innovation Strategy. Journal of Product Innovation Management, 4, 274-283. https://doi.org/10.1016/0737-6782(87)90031-2

Underwood, R. L., Klein, N. M., \& Burke, R. R. (2001). Packaging Communication: At- 
tentional Effects of Product Imagery. Journal of Product \& Brand Management, 10, 403-422. https://doi.org/10.1108/10610420110410531

Henson, B., Barnes, C., Livesey, R., Childs1, T., \& Ewart, K. (2006). Affective Requirements: A Case Study of Moisturizer Packaging. Concurrent Engineering: Research and Applications, 14, 187-196. https://doi.org/10.1177/1063293X06068358

Ares, G., \& Deliza, R. (2010). Studying the Influence of Package Shape and Colour on Consumer Expectations of Milk Desserts Using Word Association and Conjoint Analysis. Food Quality and Preference, 21, 930-937.

https://doi.org/10.1016/j.foodqual.2010.03.006

Gofman, A., Moskowitz, H. R., \& Mets, T. (2010). Accelerating Structured Consumer-Driven Package Design. Journal of Consumer Marketing, 27, 157-168. https://doi.org/10.1108/07363761011027259

Metcalf, L., Hess, J. S., Danes, J. E., \& Singh, J. (2012). A Mixed-Methods Approach for Designing Market-Driven Packaging. Qualitative Market Research: An International Journal, 15, 268-289. https://doi.org/10.1108/13522751211231987

Fernqvist, F., Olsson, A., \& Spendrup, S. (2015). What's in It for Me? Food Packaging and Consumer Responses, a Focus Group Study. British Food Journal, 117, 1122-1135. https://doi.org/10.1108/BFJ-08-2013-0224

Lin, M.-C., Wang, C.-C., Chen, M.-S., \& Chang, C. A, (2008). Using AHP and TOPSIS Approaches in Customer-Driven Product Design Process. Computers in Industry, 59, 17-31. https://doi.org/10.1016/j.compind.2007.05.013

Demirtas, E. A., Anagun, A. S., \& Koksal, G. (2009). Determination of Optimal Product Styles by Ordinal Logistic Regression versus Conjoint Analysis for Kitchen Faucets. International Journal of Industrial Ergonomics, 39, 866-875. https://doi.org/10.1016/j.ergon.2009.06.007

Lin, Y.-C., \& Wei, C.-C. (2014). The QTTI-Based TOPSIS Decision Support Model to Fragrance Form Design. 2014 International Symposium on Computer, Consumer and Control, 10-12 June 2014, 1291-1294. https://doi.org/10.1109/IS3C.2014.333

Zadeh, L. A. (1994). Fuzzy Logic, Neural Network, and Soft Computing. Communications of the ACM, 37, 77-84. https://doi.org/10.1145/175247.175255

Saaty, T. L. (1994). How to Make a Decision: The Analytic Hierarchy Process. Interfaces, 24, 19-43. https://doi.org/10.1287/inte.24.6.19

Zimmermann, H. J. (1996). Fuzzy Set Theory and Its Applications. Waltham, MA: Kluwer. https://doi.org/10.1007/978-94-015-8702-0

Wu, F.-G., Lee, Y.-J., \& Lin, M.-C. (2004). Using the Fuzzy Analytic Hierarchy Process on Optimum Spatial Allocation. International Journal of Industrial Ergonomics, 33, 553569. https://doi.org/10.1016/j.ergon.2004.01.002

McDonagh, D., Bruseberg, A., \& Haslam, C. (2002). Visual Product Evaluation: Exploring Users' Emotional Relationships with Products. Applied Ergonomics, 33, 231-240. https://doi.org/10.1016/S0003-6870(02)00008-X

Cross, N. (1994). Engineering Design Methods: Strategies for Product Design. Chichester: John Wiley \& Sons Ltd. 
Submit or recommend next manuscript to SCIRP and we will provide best service for you:

Accepting pre-submission inquiries through Email, Facebook, LinkedIn, Twitter, etc. A wide selection of journals (inclusive of 9 subjects, more than 200 journals)

Providing 24-hour high-quality service

User-friendly online submission system

Fair and swift peer-review system

Efficient typesetting and proofreading procedure

Display of the result of downloads and visits, as well as the number of cited articles Maximum dissemination of your research work

Submit your manuscript at: http://papersubmission.scirp.org/

Or contact adr@scirp.org 